\title{
The Hot Flush Beliefs Scale: A tool for assessing thoughts and beliefs associated with the experience of menopausal hot flushes and night sweats
}

\author{
Melanie J. Rendall, Laura M. Simonds \& Myra S. Hunter
}

\begin{abstract}
Objectives: Approximately 15-20 per cent of women experience their hot flushes and night sweats as problematic. There is some evidence that cognitive appraisals may help explain individual variation, and that cognitive behaviour therapy can alleviate related distress. This paper describes the development of the Hot Flush Beliefs Scale (HFBS), a questionnaire to assess women's appraisals, and reports on the reliability, validity and factor structure of the scale.
\end{abstract}

Methods: An initial pool of 63 items was generated from several sources: empirical literature, clinicians' views, and in-depth interviews, with the aim of reflecting common thoughts and beliefs about flushes and sweats. A total of 103 women, aged 41-64 years completed the initial measure. Principal components analysis and principal axis factoring were applied to the data, with both orthogonal and oblique rotation to determine the most coherent and interpretable solution. Results: Exploratory factor analysis culminated in a 27-item measure comprising three dimensions: beliefs about self in social context; beliefs about coping with hot flushes; and beliefs about coping with night sweats/sleep. The HFBS was internally consistent, with subscale alphas ranging from $0.78-0.93$, and test-retest reliability $0.74-0.78$. Validity was supported through correlations with other measures of mood and menopause beliefs.

Conclusions: Preliminary analysis of the HFBS reveals it to be a psychometrically sound instrument. The HFBS has the benefit of being grounded in women's 
experiences and shows initial promise as a tool to aid further clinical and theoretical understanding of the impact of hot flushes and night sweats.

\section{Introduction}

Although the menopause is construed as a relatively neutral event for many women [1], nearly three-quarters of women may seek advice during their menopause mainly because of hot flushes and night sweats [2]. These symptoms are associated with higher levels of distress [3] and the 15-20 per cent of women who report their hot flushes and night sweats as problematic report higher levels of social impairment, work-related complications and other difficulties such as anxiety, fatigue, and embarrassment [4-5]. Hot flushes are experienced by 65-80 per cent of women in Western cultures [6], and are typically characterised by a sudden onset of heat, sweating, flushing, anxiety and chills [7]. There is growing evidence that hot flushes are triggered by minute elevations in core body temperature within a narrowed thermoneutral zone [8-9]. These elevations may be triggered by either changes in ambient temperature or environmental triggers, such as stress, anxiety, alcohol and spicy food [10]. While the prevalence rates of night sweats are lower, their association with disturbed sleep may result in lethargy, irritability and diminished concentration [11-12].

Hormone replacement therapy (HRT) is an effective treatment [2], but since the publication of the results of the Women's Health Initiative [13] and the Million Women Study [14], there has been a decline in the use of HRT [15] and a concomitant increased use of complementary and non-hormonal treatments [16].

Current polarized explanations of menopause as 'disease' and menopause as 'natural' fail to adequately account for the individual variation in experiences of symptoms [17]. There is growing recognition of the role of psychological factors in 
mediating the perceived impact of menopause and its accompanying symptoms. For example, there is some evidence that hot flushes can occur in response to daily 'hassles' [18] or anxiety [19], and demonstrated that general levels of life stress that are likely to occur around the menopause transition may lower the threshold for triggering a hot flush [10]. Five small-scale studies [20-24] have demonstrated the effectiveness of relaxation training, with paced respiration techniques resulting in at least 50 per cent decreases in objectively measured hot flushes in samples of well women.

A cognitive behavioural model can be used to understand the possible role of psychosocial factors in the experience of hot flushes [25], which proposes that an individual's emotional and behavioural reactions to events are determined by their cognitive appraisals [26]. Cognitive schemas have been shown to account for differences in psychological responses and outcomes to a number of chronic health problems [27-28], and appraisals of hot flushes as threatening may serve to maintain individual distress, and reduce perceptions of self-efficacy [29]. Women with heightened awareness of their bodily symptoms, high levels of anxiety, and negative expectations about menopause report more frequent hot flushes and higher levels of distress $[9,30]$. Similarly, women who request treatment for hot flushes have been shown to perceive themselves as coping less well with stress, have a lower internal locus of control and lower self-esteem levels [31]. Specifically, higher levels of discomfort have been shown to be related to more extreme reactions to the physical sensations of flushing, and more negative shaming attitudes towards the self, including feeling 'unattractive', 'not needed' and 'unsuccessful' [32]. Negative automatic thoughts such as 'It is terrible and I feel like it is never going to get better' and 'I feel over-the-hill' serve to undermine feelings of competency and self-worth, 
thereby affecting levels of anxiety, mood and perceptions of control [29]. Conversely, women with low distress levels reported using encouraging self-talk and other positive behavioural strategies during flushing.

Psychological interventions, such as cognitive-behavioural therapy (CBT), have shown initial promise in alleviating the negative impact of hot flushes. Brief CBT interventions combining psycho-education, relaxation and cognitive therapy, have resulted in reductions in self-reported frequency of hot flushes [33-34].

Despite hot flushes representing the most prevalent and discomforting menopausal symptom, existing instruments provide only a limited assessment of the various dimensions of hot flushes [6]. A National Institute of Health conference concluded that the dearth of comprehensive assessment tools limits progress in the development of knowledge about hot flushes and their optimal treatment [35]. Though a recent psychosocial review concluded that assessing women's beliefs about their hot flushes could inform optimal treatment packages [36], there are currently no validated measures to achieve this suggestion. Existing studies on appraisals of hot flushes and night sweats are based on questionnaires or scales adapted from other health issues, such as arthritis and pain. The reliability and validity of these measures can be challenged, and the continued use of non-specific measurement instruments might mask the exact benefits of psychological interventions such as CBT [37]. The development of a psychometrically-sound measure of beliefs about hot flushes might result in an enhanced ability to evaluate the complexity of factors that contribute to individual differences in responding to menopausal symptoms, as well as evaluate the efficacy of interventions that target women's appraisals [25].

The main aims of this study were 1) to examine cognitive appraisals of menopausal hot flushes and night sweats, and from this, 2) to devise a 
psychometrically-sound, user-defined, self-report questionnaire measure that could significantly contribute to a more comprehensive clinical and theoretical understanding of the factors that influence the experience and impact of hot flushes and night sweats. This paper, therefore, outlines the development of the Hot Flush Beliefs Scale (HFBS), and presents initial data on its reliability, validity and factor structure.

\section{Methods}

This section is presented in two parts. Firstly, the development of the Hot Flushes Beliefs Scale (HFBS) is described. Secondly, the methods adopted to examine the psychometric properties of the HFBS are fully outlined.

\subsection{Study One: Developing the HFBS}

\subsubsection{Participants and methods}

Healthy women were recruited using leaflets placed in an acute hospital, a Breast Cancer Screening Unit, and six general practices (GP) that served a large, socially-mixed catchment area in South London. The main inclusion criterion was current experience of menopausal hot flushes and/or night sweats.

In depth semi-structured individual interviews, lasting 45-60 minutes, were conducted with four Caucasian UK women, aged between 45-60 years. At the first interview, a sentence completion task [38] was administered to obtain an overview of women's cognitions concerning self, others and the world in relation to their experience of menopause, followed by a set of open-ended questions to explore their hot flushes and night sweats. Participants were interviewed at two time points and completed modified thought records [39] in the interim period to assist with the identification of cognitions in response to hot flushes experienced in different 
situational contexts. All interviews were tape recorded with the permission of the participants, and subsequently transcribed verbatim.

\subsubsection{The development of questionnaire items}

Cognitive, behavioural and affective manifestations associated with the experience of flushes and sweats were extracted from individual interview transcripts and completed thought diaries. To maximise construct validity, statements from the individual accounts were transformed verbatim into questionnaire items. These were subsequently combined with additional items extrapolated from a variety of sources, including the extant literature, clinical judgements and clinical information from CBT groups that had been conducted with women with breast cancer who were experiencing hot flushes and night sweats, to generate a large pool of representative items covering the relevant psychological domains associated with the experience of flushes and sweats.

Amalgamation of the clinical and theoretical literature indicated that appraisals were commonly linked to specific themes relating to the social and interpersonal consequences of experiencing flushes/sweats, coping strategies, aspects of control, and beliefs about sleep. The initial version of the HFBS consisted of a total of 71 items reflecting these domains. Items were both positively and negatively worded to minimise response bias.

\subsubsection{Piloting}

Eight women who were experiencing flushes and sweats were asked to provide specific feedback on a range of factors, including layout, length, coherence, ambiguity, rating scale preference, as well as provide any pertinent additional information not covered by the questionnaire. 
The HFBS was subsequently modified on the basis of these findings to maximize conceptual clarity. Eight items were dropped, and ambiguously worded items were appropriately rewritten, culminating in a final, 63-item measure that used a six-point response scale: strongly disagree, moderately disagree, mildly disagree, mildly agree, moderately agree, strongly agree (coded as 0 to 5). Participants were instructed to "...circle the response that best describes the extent to which you agree or disagree with each statement based on your beliefs about your flushes and sweats in the past two weeks". The items included: When I have hot flushes, other people will look at me; If I'm woken up with sweats, I can manage the next day; I am coping effectively with my hot flushes.

\subsection{Study Two: Validation of the HFBS}

Following the development of the HFBS, the reliability, validity and factor structure of the new measure was examined.

\subsubsection{Participants and methods}

Healthy women were recruited from a range of local menopause clinics, GP surgeries and approved advertisements on online forums and NHS staff intranets that middle-aged women were likely to access. A further group of women were obtained through snowballing sampling. The main inclusion criteria were: current experience of hot flushes and/or night sweats, and the ability to speak, read and write English. Those who opted in via email, or by telephone, were subsequently sent a questionnaire pack and a detailed cover letter. The HFBS was part of a larger questionnaire pack that included demographic information (age, highest level of 
education, employment status, sexual orientation, ethnicity), the Menopause Representations Questionnaire [40], the Hot Flush Rating Scale [41] and the Women's Health Questionnaire [42]; these latter measures being included to assess the validity of the HFBS. As packs of questionnaires were dispensed speculatively in locations that were likely to target middle-aged women, calculating an overall response rate was not feasible.

Return of the questionnaire served as basic consent, although women were able to additionally consent to whether they would want a copy of the report findings, or be willing to fill out the questionnaire on a second occasion.

\subsubsection{Ethical issues}

The study was approved by Lewisham Local Research Ethics Committee (REC reference number 06/Q0701/38).

\subsubsection{Factor analysis of the HFBS}

A total of 103 women aged 41-64 years $($ mean $=52.70$ years; $S D=4.21)$ completed the HFBS. The sample size was considered adequate for conducting a factor analysis [43]. After a preliminary item analysis to discard any items which might show limited variability, exploratory factor analysis was conducted to examine underlying relationships and constructs measured by the HFBS items, as well as refine and reduce the number of related items to a conceptually-clear scale with optimal psychometric properties.

The two key methods of factor analysis, principal components analysis (PCA) and principal axis factoring (PFA) were considered in the identification of item 
clusters. Factor loadings were generated using both orthogonal and oblique rotations of PCA and PFA to determine the most coherent and interpretable solution.

\subsubsection{Internal consistency and test-retest analyses}

The reliability of the HFBS was examined using inter-item correlations, itemtotal correlations and Cronbach alpha coefficients. Test-retest reliability was examined by re-administering the HFBS to a subset of 16 women following a threeweek time interval.

\subsubsection{Concurrent criterion validity}

As there are no other validated measures to which the HFBS could be directly compared, concurrent criterion validity of the HFBS was investigated by correlating the HFBS scores of 103 women with relevant measures of emotional and physical health in middle-aged women, and indicators of coping with menopausal symptoms.

\section{The Women's Health Questionnaire (WHQ; 42)}

This 36-item questionnaire was developed to assess six areas of functioning in middle-aged women, including anxiety, sleep, vasomotor symptoms, depressed mood and somatic symptoms. It has been widely used in multinational clinical trials, been translated into 27 languages, and has been shown to have excellent psychometric properties, including high internal reliability (Cronbach alpha 0.7 to 0.84 ) and high test-retest reliability ( 0.78 to 0.96$)$. Three measures obtained from this questionnaire were used in the current study: (i) depressed mood subscale mean score; (ii) anxiety subscale mean score; and (iii) sleep problems subscale mean score. It was hypothesized that women who endorsed depressed mood as measured by the WHQ 
might express more negative beliefs on the HFBS. Similarly, those women who endorsed significant levels of anxiety on the WHQ might experience more negative beliefs relating to social and interpersonal consequences of having hot flushes and night sweats. Finally, it was expected that those women who endorse sleep problems on the WHQ would have more negative beliefs about night sweats on the HFBS.

\section{The Menopause Representations Questionnaire (MRQ; 40)}

The MRQ consists of 37 items developed to assess women's cognitive representations of the menopause with respect to identity, consequences, time-line and control/cure. Internal reliability (0.6 to 0.79$)$ and test-retest reliability (0.54 to 0.92$)$ were adequate. Four measures obtained from this questionnaire were used in the current study: (i) control/cure subscale mean score; (ii) negative impact subscale mean score; (iii) new phase subscale mean score; and (iv) attribution of symptoms total score. It was hypothesized that the extent to which women attribute symptoms to menopause as measured by the MRQ might be associated with positive or negative beliefs about hot flushes and night sweats. In addition, women with more negative beliefs were hypothesized to have lower perceptions of control over their symptoms, and more likely to hold beliefs that menopause had negative consequences on their life, as opposed to representing a new phase of life.

\section{The Hot Flush Rating Scale (HFRS; 41)}

The HFRS is a six-item subjective tool using one to ten numeric rating scales.

Women were asked to provide ratings of the frequency of hot flushes and night sweats, the extent to which their hot flushes and night sweats are regarded as problematic, distressing and interfering with daily life, and perceptions of their ability 
to cope or control them. Measures obtained from this questionnaire were used in the current study: (i) hot flush frequency (ii) hot flushes problem rating mean score; and (iii) coping/control subscale mean score. It was hypothesized that women with more negative beliefs on the HFBS may endorse higher problem ratings and lower perceptions of coping/control as measured by the HFRS.

\section{Results}

\subsection{Characteristics of study participants}

A total of 103 women completed the HFBS. Thirty per cent of women were recruited through advertisement for volunteers on NHS staff intranet and other internet forums, 16 per cent through the menopause clinic, 8 per cent through the breast cancer screening unit and 3 per cent through general practices, with a further 43 per cent by contacts, i.e. inviting participants to contact friends/colleagues. The sociodemographic data are similar to those reported in previous studies of middle-aged women in London (e.g. 42). Frequencies of hot flushes ranged from one to 280 per week $(25$ th percentile $=4,50$ th percentile $=14,75$ th percentile $=35)$ and frequencies of night sweats ranged from nil to 70 per week $(25$ th percentile $=2,50$ th percentile $=$ 14,75 th percentile $=21$ ). As measured by the WHQ, 97 per cent reported having hot flushes and 88 per cent night sweats.

\section{Insert table one here}

\subsection{Selection of items for factor analysis}

An item analysis was performed to reduce the number of items. Three items were deleted as over 90 per cent of the sample responded in similar ways to these 
items, indicating limited variability. The item, 'When I have hot flushes, it is best not to do anything' appeared to result in a disproportionate amount of missing data (above 5 per cent), and was therefore discarded. In order to assess whether remaining items had shared variance, item-total correlations using the correlation matrix were examined. Items presenting low correlations with the total $(\mathrm{r}<.3)$ were excluded [44]. A further 13 items were subsequently discarded, as they shared limited variance with other items in the HFBS.

A total of 46 items were retained, and preliminary analyses indicated the achieved sample and data were appropriate for exploratory factor analysis. There was a ratio of at least 2:1 participants to variables [43], and examination of the correlation matrix revealed a high proportion of correlations over 0.3 , indicating the data was factorable [45]. Kaiser and Rice's [46] Kaiser-Meyer-Olkin (KMO) measure of sampling adequacy was 0.844 , and Bartlett's test of sphericity was significant ([chi square $]=3326.12, \mathrm{p}<.001)$, indicating high sampling adequacy [47].

\subsection{Factor structure of the HFBS}

The HFBS responses were analysed using principal axis factoring (PFA) (principal components analysis yielded similar results). Cattell's scree test criteria [48] and Kaiser's criteria [49] were considered to determine the number of factors to extract. Although the unrotated solution revealed 10 factors with eigenvalues $>1$, use of the scree plot is considered a more accurate determination of which factors to retain [50]. As the scree plot demonstrated a break in the slope between factors three and four, a three factor solution was indicated, which accounted for 48.78 per cent of the variance (range of eigenvalues $2.28-16$ ). 
Although psychological constructs are generally assumed to correlate, thereby indicating an oblique method of rotation, an orthogonal technique (Varimax) was favoured to determine the existence of independent factors [51]. Three distinct dimensions were obtained based on item content, and were well marked by at least five items each. The criterion for inclusion in a factor was set at 0.512 , in line with standard recommendations with a sample size of 100 [52]. Table 2 outlines the items and the item statistics. Factor one accounted for 34.78 per cent of the variance, and consisted of 16 items such as 'when I have a hot flush, I am embarrassed' and 'other people's reactions to my hot flushes don't bother me', and was entitled Beliefs about Self in Social Context. Factor two accounted for 9.04 per cent of the variance, and consisted of 10 items such as 'I am coping effectively with my hot flushes' and 'when I have a hot flush, I think when will they ever end', and was entitled Beliefs about Coping With Hot Flushes. Factor three accounted for 4.96 per cent of the variance, and consisted of five items such as 'when I have night sweats I won't be able get back to sleep' and 'when I have night sweats, it is harder to cope the next day', and was entitled Beliefs about Coping with Night Sweats/Sleep. All items >0.512 loaded highly on only one factor. Oblique rotation was also run, using similar steps, to ascertain how robust the factors were. Though factors one and two yielded identical results, factor three contained three items compared with the five indicated with orthogonal rotation.

Insert table 2 here

The determinant of the correlation matrix was greater than 0.00001 , indicating that multicollinearity (i.e. variables that are highly correlated) and singularity (i.e. 
variables that are perfectly correlated) was not a threat to data integrity. The correlation matrix was subsequently reexamined, however, to identify whether there were variables that were correlating very highly $(\mathrm{R}>0.8)$ [47]. Although high correlations between variables were not present, the items indicated through oblique and orthogonal rotation techniques were discussed with a health professional expert to examine the conceptual clarity of specified beliefs. Four items were subsequently discarded due to being similarly worded, as well as correlating highly together ( $\mathrm{r}>$ 0.7). In addition, the orthogonal solution was deemed the most coherent solution based on clinical experience.

In sum, after taking into account statistical results and clinical interpretability, a total of 27 items were retained in the HFBS, with three subscales based on the factor analysis (Subscale $1=13$; Subscale $2=10$; Subscale $3=4$ ). The responses to the three subscales were normally distributed. Higher scores on the HFBS are indicative of higher numbers of negative beliefs. Table 3 shows the distribution of responses and means (s.ds.) for the HFBS subscales. The final questionnaire is shown in Appendix 1.

Insert table 3 here

\subsection{Internal consistency of subscales}

Internal consistency was assessed for the total 27-item scale and for each separate subscale. Cronbach coefficient alphas computed for the individual HFBS subscales $(\mathrm{N}=103)$ were as follows: beliefs about self in social context $=0.93$; beliefs about coping with hot flushes $=0.89$; beliefs about coping with night sweats/sleep $=0.78$. These findings indicate that all subscales are consistently 
measuring one underlying factor, proportionately measure true score, and therefore have good reliability. Results for the total scale (0.94) reflected the general consistency of the measure.

\subsection{Subscale inter-correlations}

Pearson correlations between the means of the individual subscales of the HFBS are reported in Table 4, showing that all three subscales were significantly positively correlated with each other in the present sample.

Insert table 4 here

\subsection{Test-retest reliability}

Test-retest reliability of both total and dimensional scales was assessed using a Pearson product-moment correlation between two consecutive administrations of the HFBS with a three-week interval on a sub-sample of 16 participants. Results show the stability of the measure across time with a moderate correlation for the total scale $(\mathrm{r}=$ $0.72, \mathrm{p}<.01)$ and moderate correlations when considering the three subscales assessed $(1: \mathrm{r}=0.75, \mathrm{p}<.01 ; 2: \mathrm{r}=0.74, \mathrm{p}<.01 ; 3: \mathrm{r}=0.78, \mathrm{p}<.01)$.

\subsection{Content validity}

Content validity was maximized by ensuring items were generated through a systematic exploration of the existing literature, interviews with women, and consultation with health professionals knowledgeable about common appraisals of hot flushes and night sweats. The low proportion of missing data from women completing the HFBS indicated high content validity. 


\subsection{Concurrent criterion validity}

To determine whether the three factors emanating from PFA were 'true' factors and not merely an artefact arising from the inclusion of items that are similarly worded [43], correlations were calculated between HFBS subscales and other subscales of the standardized measures completed by the sample. Spearman correlations were used as the distributions of the hot flush rating scale and mood were slightly skewed. Table 5 outlines the results.

\section{Insert table 5 here}

As hypothesized, there were significant positive correlations between WHQ depressed mood and all three subscales of the HFBS; there was a large effect size for depressed mood scores and negative beliefs about coping with hot flushes and night sweats/sleep (subscales 2 and 3), and a moderate effect size with beliefs about self in social context (subscale 1). The correlations also showed that higher scores on all three HFBS subscales were significantly associated with higher levels of anxiety. As expected, those women who endorsed sleep problems on the WHQ exhibited more negative beliefs about night sweats on the HFBS. There were significant positive associations between frequencies of hot flushes and night sweats and negative beliefs, although the overall magnitude was small.

As hypothesized, there was a strong association between negative beliefs on the HFBS and higher problem rating scores on the HFRS, indicating that women who perceived their hot flushes to be a problem, distressing, and as interfering with their daily functioning were more likely to display a range of negative thoughts and beliefs 
about their symptoms. Furthermore, there was a significant negative association between coping/control and negative appraisals, suggesting that women with lower perceptions of coping/control as measured by the HFRS experienced more negative beliefs.

Correlations suggested that the extent to which women attribute symptoms to menopause as measured by the MRQ was associated with beliefs about hot flushes and night sweats; as expected, women who experienced more negative beliefs attributed more of their symptoms to the menopause. In addition, women with more negative beliefs were significantly more likely to hold beliefs that menopause had negative consequences on their life, and less likely to view their menopause as a new phase of their lives.

\section{Discussion}

In this study, we examined cognitive appraisals of menopausal hot flushes and night sweats, and devised a psychometrically-sound measure to assess these beliefs and appraisals.

Principal axis factoring (PFA) of initial HFBS items followed by an examination of eigenvalues $>1$ and the scree test indicated a three factor solution, which was subsequently rotated using an orthogonal procedure to obtain simple structure. The content of these factors suggested that the HFBS was measuring dimensions of beliefs about self in social context, beliefs about coping with hot flushes, and beliefs about coping with night sweats/sleep. The internal consistency and test-retest reliability of the three subscales of the HFBS was moderate to high, indicating that the questionnaire was a reliable measure that was moderately stable over the course of time. Correlational analyses demonstrated a number of 
relationships in the expected directions between the subscales of the HFBS and other measures of women's emotional, cognitive and physical health, suggesting that the HFBS was a valid measure that was capturing something meaningful.

The wide variety of responses across all items of the HFBS suggested good discriminatory power. Furthermore, the spread of scores was consistent with what is known from the wider literature; while many women have positive or neutral appraisal of menopausal symptoms, a significant minority experience a range of negative beliefs related to the social and interpersonal consequences of hot flushes, as well as their ability to cope with flushes and sweats [31]. Study findings, therefore, confirmed that the experience of hot flushes and night sweats activates cognitive, behavioral and affective systems and the results strongly indicate that women's cognitive appraisals may have a substantial role in maintaining distress, or exacerbating physiological responses. Specifically, the association of more negative scores on the HFBS with higher distress ratings and lower perceptions of control/coping as measured by the WHQ, MRQ and the HFRS indicate that treatments that help women to manage their psychological responses to the physical sensations of flushes and sweats by addressing their cognitive appraisal of the event, and moderating the subjective feelings of hopelessness or lack of control, may be fruitful. The low correlation between frequency of flushes/sweats and negative cognitive appraisals corroborates previous assertions that continued reliance on frequency ratings as the single outcome measure in clinical practice and research might be too narrow, and that other dimensions, such as distress, need to be incorporated into future studies [40]. A particular strength of the HFBS is its high content and face validity; specified thoughts and beliefs were generated from a variety of sources, including in-depth interviews with menopausal women, clinical health 
psychologists, and clinical information from psychological treatment group, enabling it to be firmly grounded in women's experiences.

The HFBS was validated on a sample that reflected the population for whom the measure was intended. Although the sample was overwhelmingly white, heterosexual and well-educated, it did reflect a range of severity as measured by frequency of hot flushes and night sweats, and on additional measures of emotional and physical functioning. This heterogeneity increases the robustness and validity of the findings of this study, as it does not appear that the self-selecting sample of women solely represented those at the more negative end of the spectrum. However, caution must be expressed with respect to the sample size; this study's sample of 103 represented the absolute minimum requirement for conducting a factor analysis.

Though the HFBS revealed adequate reliability and validity, findings need to be interpreted with caution. Future research is needed to replicate the existing findings, ideally with a larger, more socially and ethnically diverse sample. Future research is also needed to examine the measure's sensitivity to treatment effects, for example, does the delivery of CBT, or other psychosocial interventions, result in the modification in cognitive appraisals as measured by the HFBS. The main aim of the current study was not to test hypotheses regarding the precise relationships of emotional and cognitive reactions to the experience of hot flushes and night sweats, but rather to develop a measure that assesses thoughts and beliefs about menopausal symptoms in a systematic way. Confirmatory factor analysis (CFA), a technique designed for use in the advanced stages of the research process, is needed in further studies to test specific hypotheses about the relationship of cognitive appraisals to the experience of hot flushes and night sweats via inferential techniques [44]. Lastly, it might be practical to develop a briefer version for use in clinical settings, e.g. for 
screening or targeted intervention outcome assessment. Future research may therefore result in further refinement of the HFBS.

\section{Conclusion}

The HFBS was developed to assess women's cognitive appraisals of their hot flushes and night sweats. Preliminary analyses indicate that systematic use of this reliable and valid measure could contribute to an increased understanding of the relationship of cognitions to the experience of hot flushes and night sweats, help delineate reasons for individual differences in response to menopausal symptoms, and both inform and evaluate psychological treatment interventions to alleviate distress.

\section{References}

[1] Dennerstein L, Lehert P, Burger H, Dudley E. Mood and the menopausal transtion. J Nerv Ment Dis 1999; 187: 685-91.

[2] Hope S, Wagner E, Rees M. Survey of British women's views on the menopause and HRT. J Brit Meno Soc 1998; 4: 33-36.

[3] Ford K, Sowers M, Crutchfield MW, Wilson A, Jannausch M. A longitudinal study of the predictors of prevalence and severity of symptoms commonly associated with menopause. Menopause 2005; 12: 308-317.

[4] Kronenberg F. Hot flashes - Epidemiology and physiology. Ann NY Acad Sci 1990; 592: 52.

[5] Utian WH. Psychosocial and socioeconomic burden of vasomotor symptoms in menopause - A comprehensive review. Health Qual Life Outcomes 2005; 3: 47-57. [6] Ratka A, Miller V, Brown K et al. Menopausal vasomotor symptoms (MVS) survey for assessment of hot flashes. J Wom Health 2006; 15: 77-89. 
[7] Mom CH, Buijs C, Willemse PHB, Mourits MJE, de Vries EGE. Hot flushes in breast cancer patients. Crit Rev Onc/Haem 2006; 57: 63-77.

[8] Freedman RR. Pathophysiology and treatment of menopausal hot flashes: A contemporary approach to the menopause. Sem Reprod Med 2005; 23: 117-25. [9] Freedman RR. Hot flashes: Behavioural treatments, mechanisms, and relation to sleep. Am J Med 2005; 118: 1245-1305.

[10] Swartzman LC, Edelberg R, Kemmann E. Impact of stress on objectively recorded menopausal hot flushes and on flush report bias. Health Psychol 1990; 9: $529-45$.

[11] Mohyi D, Tabassi K, Simon, J. Differential diagnosis of hot flashes. Maturitas 1997; 27: 203-14.

[12] Sievert LL, Obermayer CM, Price, K. Determinants of hot flashes and night sweats. Ann Hum Biol 2006; 33: 4-16.

[13] Roussouw JE, Anderson GL, Prentice RL. Risks and benefits of oestrogen plus progestin in healthy postmenopausal women - Principal results from the Women's Health Initiative randomized controlled trial. JAMA 2002; 288: 321-33.

[14] Beral V, Banks E, Reeves $\mathrm{G}$ et al. Breast cancer and hormone replacement therapy in the Million Women study. Lancet 2003; 362: 419-27.

[15] Menon U, Burnell M, Sharma A et al. Decline in use of hormone therapy among postmenopausal women in the United Kingdom. Menopause 2007; 14: 462-67.

[16] Kagan L, Dusek JA. Mind/body interventions for hot flashes. Menopause 2006; 13: 727-29.

[17] Hunter MS, O’Dea I. Menopause: bodily changes and multiple meanings. In: Ussher JM, ed. Body talk - the material and discursive regulation of sexuality, madness and reproduction. London: Routledge, 1997; 199-222. 
[18] Gannon L, Hansel S, Goodwin J. Correlates of menopausal hot flushes. J Behav Med 1987; 10: 277-85.

[19] Slade P, Amaee S. The role of anxiety and temperature in the experience of menopausal hot flushes. J Reprod and Infant Psych 1995; 43: 127-34.

[20] Freedman RR, Woodward S. Behavioural treatment of menopausal hot flushes Evaluation by ambulatory monitoring. Am J Obstet and Gynecol 1992; 167: 436-39. [21] Germaine LM, Freedman RR. Behavioural treatments of menopausal hot flushes - evaluation by ambulatory monitoring. J Consult Clin Psych 1994; 52: 1072-79. [22] Irvin JH, Domar AD, Clark C, Zuttermeister PC, Friedman R. The effects of relaxation response training on menopausal symptoms. J Psychosom Obst Gyn 1996; 17: 202-207.

[23] Stevenson DW, Delprato DJ. Multiple component self control programme for menopausal hot flushes. J Behav Ther Exp Psy 1983; 14: 137-40.

[24] Wijima K, Melin MA, Nedstrand E, Hammer M. Treatment of menopausal symptoms with applied relaxation: A pilot study. J Behav Ther Exp Psy 1997; 28|: 251-61.

[25] Hunter M, Rendall M. Bio-psycho-socio-cultural perspectives on menopause. Best Pract Res Cl Ob 2007; 21: 261-74.

[26] Beck AT. Cognitive therapy and the emotional disorders, New York: International Universities Press, 1976 [27] Lacroix JM, Martin B, Avendano M, Goldstein R. Symptom schemata in chronic respiratory patients. Health Psychol 1991; 10: 268-73.

[28] White CA. Cognitive behavioural therapy for chronic medical problems, New York: Wiley, 2001 
[29] Reynolds F. Relationship between catastrophic thoughts, perceived control and distress during menopausal hot flushes - exploring the correlates of a questionnaire measure. Maturitas 2000; 36: 113-22.

[30] Avis NE, McKinlay SM. A longitudinal analysis of women's attitudes towards the menopause - results from the Massachusetts women's health study. Maturitas 1991; 13: 65-79.

[31] Hunter MS, Liao KLM. Determinants of treatment choice for menopausal hot flushes: Psychological, hormonal or no treatment. J Psychosom Obst Gyn 1995; 16: 101-08.

[32] Reynolds F. Exploring self-image during hot flushes using a semantic differential scale: associations between poor self-image, depression, flush frequency and flush distress. Maturitas 2002; 42: 201-07.

[33] Keefer L, Blanchard EB. A behavioural group treatment program for menopausal hot flashes. Appl Psychophys Biof 2005; 30: 21-30.

[34] Hunter MS, Liao LM. Evaluation of a four-session cognitive-behavioural intervention for menopausal hot flushes. Brit J Health Psych 1996; 1: 113-25. [35] Miller HG, Li RM. Measuring hot flushes - Summary of a National Institutes of Health Workshop. Mayo Clin Proc 2004; 79: 777-81.

[36] Towey M, Bundy C, Cordingley L. Psychological and social interventions in the menopause. Curr Opin Obstet Gyn 2006; 18: 413-17.

[37] Keefer L, Blanchard EB. Hot flash, hot topic - Conceptualising menopausal symptoms from a cognitive-behavioural perspective. Appl Psychophys Biof 2005; 30: 75-82.

[38] Padesky CA. Schema change processes in cognitive therapy. Clin Psychol Psychot 1994; 1: 267-78. 
[39] Greenberger D, Padesky CA. Mind over mood - Change how you feel by changing the way you think, New York: The Guildford Press, 1995

[40] Hunter M, O’Dea I. Cognitive appraisal of the menopause - The development of the menopause representations questionnaire (MRQ). Psychol Health Med 2001; 6: $65-76$.

[41] Hunter MS, Liao LM. A psychological analysis of menopausal hot flushes. Brit J Clin Psychol 1995; 34: 589-99.

[42] Hunter MS. The Women's Health Questionnaire - A measure of mid-aged women's perceptions of their emotional and physical health. Psychol Health 1992; 7: 45-54.

[43] Kline P. An easy guide to factor analysis, London: Routledge, 1994

[44] Rust J, Golombok S. Modern Psychometrics - The Science of Psychological Assessment, $2^{\text {nd }}$ edn, New York: Routledge, 1999

[45] Tabachnick BG, Fidell LS. Using multivariate statistics, $4^{\text {th }}$ edn, Needham Heights, MA: Allyn \& Bacon, 2001

[46] Kaiser HF, Rice J. Little Jiffy, Mark IV. Educ Psychol Meas 1974; 34: 111-17.

[47] Field A. Discovering statistics using SPSS for Windows - Advanced techniques for the beginner, London: Sage, 2001

[48] Cattell RB. The scree test for the number of factors. Multivar Behav Res 1966; 1: 245-76.

[49] Kaiser HF. The application of electronic computers to factor analysis. Educ Psychol Meas 1960; 20: 141-51.

[50] Preacher KJ, MacCullum RC. Repairing Tom Swift's electric factor analysis machine. Under Stat 2003; 2: 13-43.

[51] Blaikie N. Analyzing quantitative data, London: Sage, 2003 
[52] Stevens JP. Applied multivariate statistics for the social sciences, $2^{\text {nd }}$ edn, Hillsdale, NJ: Erlbaum, 1992 
Table 1: Socio-demographics of the study sample

\begin{tabular}{|c|c|c|}
\hline Demographic/Characteristics & $\mathrm{N}$ & $\%$ \\
\hline Living status & 103 & \\
\hline Single/Never married & 10 & 9.5 \\
\hline Married/Living with Partner & 76 & 74 \\
\hline Divorced/Separated & 13 & 12.5 \\
\hline Widowed & 4 & 4 \\
\hline Sexual Orientation & 101 & \\
\hline Heterosexual & 93 & 92 \\
\hline Lesbian & 7 & 7 \\
\hline Bisexual & 1 & 1 \\
\hline Employment & 102 & \\
\hline Full-time & 55 & 54 \\
\hline Part-time & 28 & 27 \\
\hline Retired & 8 & 8 \\
\hline Housewife & 4 & 4 \\
\hline Disabled & 7 & 7 \\
\hline Education & 103 & \\
\hline$<16$ years & 28 & 27 \\
\hline$<18$ years & 12 & 12 \\
\hline Degree and beyond & 63 & 61 \\
\hline Ethnicity & 103 & \\
\hline White & 98 & 95 \\
\hline Black or Black British & 4 & 4 \\
\hline Other Ethnic Group & 1 & 1 \\
\hline Stage of Menopause & 102 & \\
\hline Not started yet & 3 & 3 \\
\hline Very early stages & 12 & 12 \\
\hline In the middle & 51 & 50 \\
\hline Towards the end & 31 & 30 \\
\hline Gone through the menopause & 5 & 5 \\
\hline
\end{tabular}




\begin{tabular}{|c|c|c|c|c|c|c|}
\hline \multirow[b]{2}{*}{ HFBS Item } & \multicolumn{3}{|c|}{ Factor loadings } & \multirow[b]{2}{*}{ M } & \multirow[b]{2}{*}{$\mathrm{SD}$} & \multirow[b]{2}{*}{$h^{2}$} \\
\hline & Factor 1 & Factor 2 & Factor 3 & & & \\
\hline $\begin{array}{l}\text { 49. Having hot flushes makes me more } \\
\text { concerned with what other people think of } \\
\text { me. }\end{array}$ & .80 & .18 & .07 & 1.70 & 1.56 & .67 \\
\hline 21. When I have a hot flush, I am embarrassed. & .74 & .26 & .07 & 2.36 & 1.76 & .61 \\
\hline $\begin{array}{l}\text { 42. When I have hot flushes, I look stupid in } \\
\text { front of others. }\end{array}$ & .73 & .11 & .27 & 1.21 & 1.59 & .61 \\
\hline $\begin{array}{l}\text { 23. When I have a hot flush, I am anxious about } \\
\text { how I look. }\end{array}$ & .73 & .26 & .13 & 2.74 & 1.66 & .61 \\
\hline $\begin{array}{l}\text { 17. When I have a hot flush in front of people, I } \\
\text { am anxious. }\end{array}$ & .72 & .27 & -.02 & 2.60 & 1.57 & .59 \\
\hline $\begin{array}{l}\text { 28. When I have a hot flush, other people will } \\
\text { think I am incompetent. }\end{array}$ & .70 & .04 & .14 & 1.16 & 1.38 & .50 \\
\hline 44. When I have hot flushes, I feel incompetent. & 68 & .08 & .45 & 1.12 & 1.40 & .67 \\
\hline $\begin{array}{l}\text { 34. When I have a hot flush, other people will } \\
\text { think there is something wrong with me. }\end{array}$ & .67 & .33 & .11 & 1.92 & 1.53 & .58 \\
\hline $\begin{array}{l}\text { 57. Other people's reactions to my hot flushes } \\
\text { do not bother me. }\end{array}$ & .66 & .15 & .08 & 1.64 & 1.56 & .47 \\
\hline 26. Hot flushes make me feel unattractive. & .65 & .30 & .17 & 2.39 & 1.69 & .54 \\
\hline $\begin{array}{l}\text { 1. When I have hot flushes, other people will } \\
\text { look at me. }\end{array}$ & .64 & .17 & .14 & 2.41 & 1.56 & .46 \\
\hline 12. Hot flushes make me feel stupid. & .64 & .03 & .33 & 1.08 & 1.54 & .52 \\
\hline $\begin{array}{l}\text { 31. When I have a hot flush, I don't care what } \\
\text { other people think. }\end{array}$ & .55 & .26 & -.12 & 2.06 & 1.66 & .39 \\
\hline $\begin{array}{l}\text { 54. When I have hot flushes, I feel I am the } \\
\text { centre of attention. }\end{array}$ & .55 & .18 & .13 & 1.37 & 1.45 & .36 \\
\hline 47. When I have a hot flush, I feel useless. & .53 & .25 & .35 & 1.25 & 1.54 & .47 \\
\hline $\begin{array}{l}\text { 36. It is best to avoid social situations if I am } \\
\text { having hot flushes. }\end{array}$ & .53 & .22 & .11 & 1.19 & 1.44 & .34 \\
\hline $\begin{array}{l}\text { 2. I am able to cope with the physical discomfort } \\
\text { of hot flushes. }\end{array}$ & .08 & .69 & .28 & 2.06 & 1.48 & .56 \\
\hline 46. I feel overwhelmed by my hot flushes. & .22 & .68 & .26 & 2.39 & 1.77 & .58 \\
\hline 43. I am coping effectively with my hot flushes. & .30 & .67 & .37 & 1.85 & 1.59 & .67 \\
\hline 37. When I have a hot flush, I can ignore them. & .27 & .66 & .14 & 3.11 & 1.71 & .53 \\
\hline 15. I don't let hot flushes get me down. & .29 & .64 & .33 & 1.34 & 1.42 & .60 \\
\hline $\begin{array}{l}\text { 38. Other people seem to manage their hot flushes } \\
\text { better than I do. }\end{array}$ & .11 & .62 & .17 & 1.68 & 1.46 & .42 \\
\hline 59. When I have hot flushes, I feel irritated. & .24 & .61 & .11 & 3.00 & 1.52 & .44 \\
\hline $\begin{array}{l}\text { 63. When I have a hot flush, I think when will } \\
\text { they ever end. }\end{array}$ & .18 & .58 & .26 & 2.96 & 1.85 & .44 \\
\hline 45. I feel resentful of my hot flushes. & .23 & .56 & .04 & 2.85 & 1.75 & .37 \\
\hline $\begin{array}{l}\text { 58. I worry about when I am going to have } \\
\text { another hot flush. }\end{array}$ & .22 & .55 & -.09 & 1.80 & 1.71 & .36 \\
\hline $\begin{array}{l}\text { 50. When I have night sweats, it is harder to cope } \\
\text { the next day. }\end{array}$ & .12 & .25 & .76 & 2.35 & 1.61 & .65 \\
\hline $\begin{array}{l}\text { 22. When I have night sweats, I know the next } \\
\text { day will be harder. }\end{array}$ & .27 & .25 & .71 & 1.98 & 1.61 & .64 \\
\hline $\begin{array}{l}\text { 14. If I'm woken up with sweats, I can manage } \\
\text { the next day. }\end{array}$ & .06 & .24 & .68 & 1.78 & 1.55 & .53 \\
\hline $\begin{array}{l}\text { 6. When I have night sweats, I won't be able to } \\
\text { get back to sleep. }\end{array}$ & .16 & .25 & .55 & 2.56 & 1.61 & .39 \\
\hline $\begin{array}{l}\text { 60. Night sweats don't affect my } \\
\text { general health. }\end{array}$ & .09 & .42 & .54 & 2.14 & 1.75 & .47 \\
\hline
\end{tabular}

Note. HFBS $=$ Hot Flush Beliefs Scale. Unique factor loadings $>0.512$ are in bold. Analysis is based on 103 observations. HFBS item ratings range from 0 to 5 . Likert scale anchors ranged from $0=$ strongly disagree to $5=$ strongly agree. Factor $1=$ Beliefs about self in social context; Factor 2 = Beliefs about coping with hot flushes; Factor 3 = Beliefs about coping with night sweats/sleep; $\mathrm{M}=$ mean; $\mathrm{SD}=$ standard deviation; $h^{2}=$ item communalities at extraction. 
Table 3: Percentage distribution of responses for the HFBS subscales $(\mathrm{N}=103)$

\begin{tabular}{lcccc}
\hline Response scale & $\begin{array}{c}\text { Beliefs about self } \\
\text { in social context }\end{array}$ & $\begin{array}{c}\text { Beliefs about coping } \\
\text { with hot flushes }\end{array}$ & $\begin{array}{c}\text { Beliefs about coping } \\
\text { with night sweats/sleep }\end{array}$ & Total HFBS \\
\hline Strongly Disagree & 31 & 21 & 19 & 24 \\
Moderately Disagree & 17 & 18 & 21 & 19 \\
Mildly Disagree & 12 & 15 & 14 & 14 \\
Mildly Agree & 21 & 18 & 20 & 19 \\
Moderately Agree & 10 & 12 & 14 & 12 \\
Strongly Agree & 9 & 15 & 12 & 2.13 \\
Mean* & 1.87 & 2.30 & 2.21 & 1.61 \\
SD* & 1.56 & 1.63 & 1.63 & \\
\hline
\end{tabular}

Note. $*$ Likert scale were as follows: $0=$ strongly disagree; $1=$ moderately disagree; $2=$ mildly disagree; $3=$ mildly agree $; 4=$ moderately agree; $5=$ strongly agree

Table 4: HFBS subscale inter-correlations $(\mathrm{N}=103)$

\begin{tabular}{llllc}
\hline HFBS subscale & 1 & 2 & 3 & Total HFBS \\
\hline $\begin{array}{l}\text { 1. Beliefs about self in } \\
\text { Social context. }\end{array}$ & - & $0.58^{* *}$ & $0.38^{* *}$ & $0.84^{* *}$ \\
$\begin{array}{l}\text { 2. Beliefs about coping } \\
\text { with hot flushes. }\end{array}$ & - & - & $0.59^{* *}$ & $0.88^{* *}$ \\
$\begin{array}{l}\text { 3. Beliefs about coping } \\
\text { with night sweats/sleep. }\end{array}$ & - & - & - & $0.67^{* *}$ \\
\hline
\end{tabular}

Two-tailed significance: ** correlation is significant at the 0.01 level

Table 5: Correlations between the HFBS and other symptom measures

\begin{tabular}{|c|c|c|c|c|}
\hline & $\begin{array}{l}\text { Beliefs about self } \\
\text { in social context }\end{array}$ & $\begin{array}{l}\text { Beliefs about coping } \\
\text { with hot flushes }\end{array}$ & $\begin{array}{c}\text { Beliefs about coping } \\
\text { with night sweats/sleep }\end{array}$ & Total HFBS \\
\hline WHQ Depression Subscale & $0.26 * *$ & $0.59 * *$ & $0.51 * *$ & $0.51 * *$ \\
\hline WHQ Sleep Subscale & $0.23^{*}$ & $0.34 * *$ & $0.41^{* *}$ & $0.37 * *$ \\
\hline HFRS Problem Rating & $0.53 * *$ & $0.69^{* *}$ & $0.52 * *$ & $0.70^{* *}$ \\
\hline HFRS Coping/Control Rating & $-0.48 * *$ & $-0.66^{* *}$ & $-0.63 * *$ & $-0.66 * *$ \\
\hline MRQ Negative Consequences & $0.53 * *$ & $0.66^{* *}$ & $0.53^{* *}$ & $0.69^{* *}$ \\
\hline MRQ New Phase & $-0.28 * *$ & $-0.41^{* *}$ & $-0.29 * *$ & $-0.37 * *$ \\
\hline Frequency of flushes and sweats & $0.23^{*}$ & $0.39^{* *}$ & $0.22 *$ & $0.35^{* *}$ \\
\hline
\end{tabular}

Two-tailed significance: * correlation is significant at the 0.05 level; ** correlation is significant at the 0.01 level

Note. Correlations based on N = 103 (except HFRS Problem, HFRS Coping/Control =101), and calculated on mean scores for total scale and subscales of the HFBS, and mean scores for subscales. WHQ = Women's Health Questionnaire; HFRS = Hot Flush Rating Scale; MRQ = Menopause Representation Questionnaire; Subscale 1 = Beliefs about self in social context; Subscale 2 = Beliefs about coping with hot flushes; Subscale 3 = Beliefs about coping with night sweats/sleep; HFBS = Hot Flush Beliefs Scale. Frequency of hot flushes and night sweats represented the weekly total estimated by participants. 